\title{
Finite element analysis of the compaction plate from a garbage truck
}

\author{
Gheorghe Voicu ${ }^{1}$, Mircea Lazea ${ }^{1}$, Gabriel-Alexandru Constantin ${ }^{1, *}$, Elena-Madalina \\ Stefan $^{1}$, and Mariana-Gabriela Munteanu ${ }^{1}$ \\ ${ }^{1}$ Politehnica University of Bucharest, Faculty of Biotechnical Systems Engineering, Romania
}

\begin{abstract}
Vehicles that collect and transport household waste are equipped with complex systems that perform the loading of the waste from the stationary collection containers, take over and pre-compact of material, compaction in the body of the structure and finally the landfill of the collected waste. Of all these operations, the compaction process is by far the most mechanically demanding. In this paper, the structural analysis of the compactor plate from a garbage truck is presented. In the first stage it was carried out parametric modelling of the assembly composed of compactor plate, counter pressure plate, the back of the garbage truck and to be compacted material. After assembly, the dynamic simulation of the compaction process in the garbage truck was performed, and the compaction mechanical stresses for the compactor plate were loaded in the Simulation module of the SolidWorks 2016 program. Here the finite element analysis was performed, resulting in the value and dispersion of the equivalent stresses (calculated by von Mises criterion), displacements and relative deformations of compactor plate from the analysed garbage truck.
\end{abstract}

\section{Introduction}

Manufacture of component parts for garbage trucks, but also of other machines and equipments, assumes that their physical model to have followed, in the conception and design stage, several steps in which the design engineers have subjected it to modelling, simulation and analysis with specialized software operations, before being sent to execution. In this way, many possible manufacturing errors, which may occur in these component parts, can be eliminated. In the case of mechanical stresses, the most common method of analysis is finite element analysis. There are many such analyses in the literature, even in the case of municipal waste trucks, [1-4].

The purpose of this finite element 3D numerical simulation study was to simulate the behaviour of the compression plate structure of a garbage truck Valu€ Pak 1000 following the stresses that arise during the compaction process of household waste, considering that the plate is made of three different materials (Hardox 400, Hardox 450 and S355J2 steels).

The waste compaction system of such a machine consists of two basic parts, a metal plate with hinged support that takes over the material from the machine's feed area, having

\footnotetext{
* Corresponding author: constantin.gabriel.alex@gmail.com
} 
a complex movement, and a counter plate disposed in the rectangular collection container (see fig. 1).

- two yoke cylinders
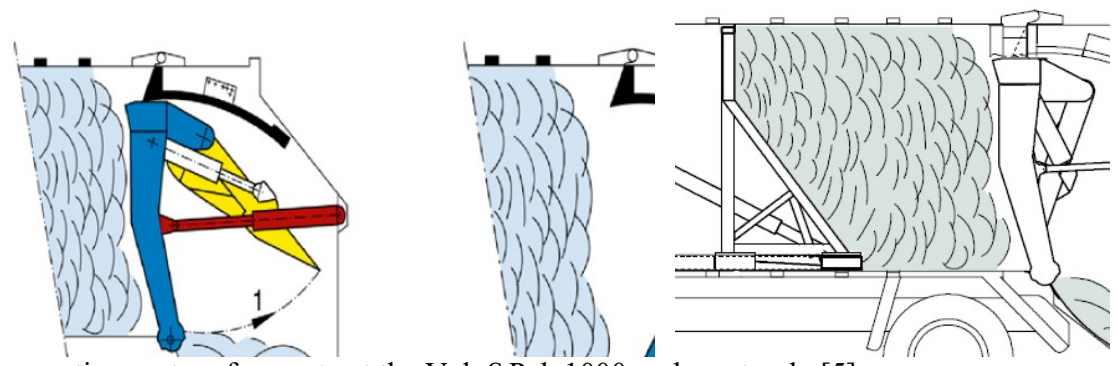

Fig. 1 Compaction system for waste at the Valu€ Pak 1000 garbage truck, [5].

In both pieces important stresses appear during the collection and compaction process, but much larger in the pushing and retrieval piece when feeding the container. At discharging, the back pressure plate has high demands because it has to push the entire amount of material from the container, the more uneven the material is more homogeneous on the cross-section of the collection container.

\section{Material and method}

In the first stage of this study, the three-dimensional geometric model of the components of the assembly was realized (compression plate, back pressure plate, wear part and the container). So, an ASUS K55V laptop was used, containing an Intel Core i5-3210M, 2.5GHz, NVIDIA GeForce GT 630M video card with $2 \mathrm{~GB}$ of memory, $8 \mathrm{~GB}$ of RAM. 3D modelling was performed with the help of the parameterized design program Solid Works Premium 2016 S.P. 0.0.

The three-dimensional modelling of the components of the assembly was performed in the module "Parts" of the design program, in fig. 2 being presented the isometric view of the compaction plate, as well as the Solid Works program interface.

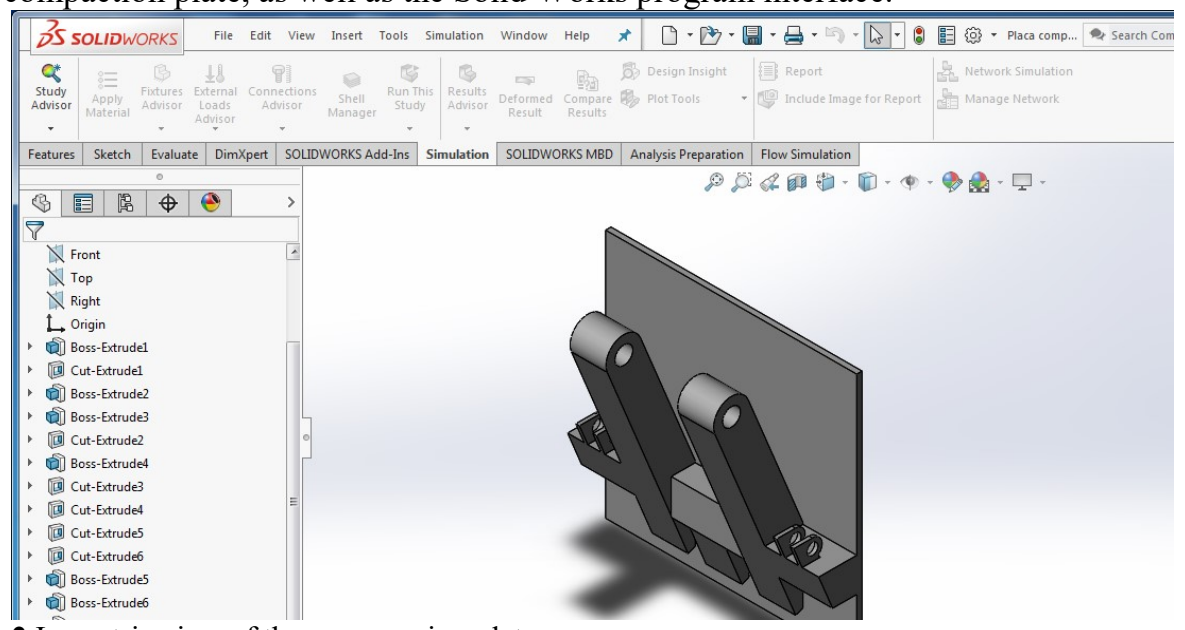

Fig. 2 Isometric view of the compression plate

The pieces were introduced in the Assembly module of the program where they were positioned by adding geometric relationships between their entities (concentricity relations, coincidence and parallelism between the edges and faces, and others). For the dynamic 
simulation of the compaction process of household waste, between the two plates (of compaction and counterpressure) it was modelled parameterized the material to be compacted. For this, a thickness at the bottom of about $580 \mathrm{~mm}$ was chosen, see fig. 3 .

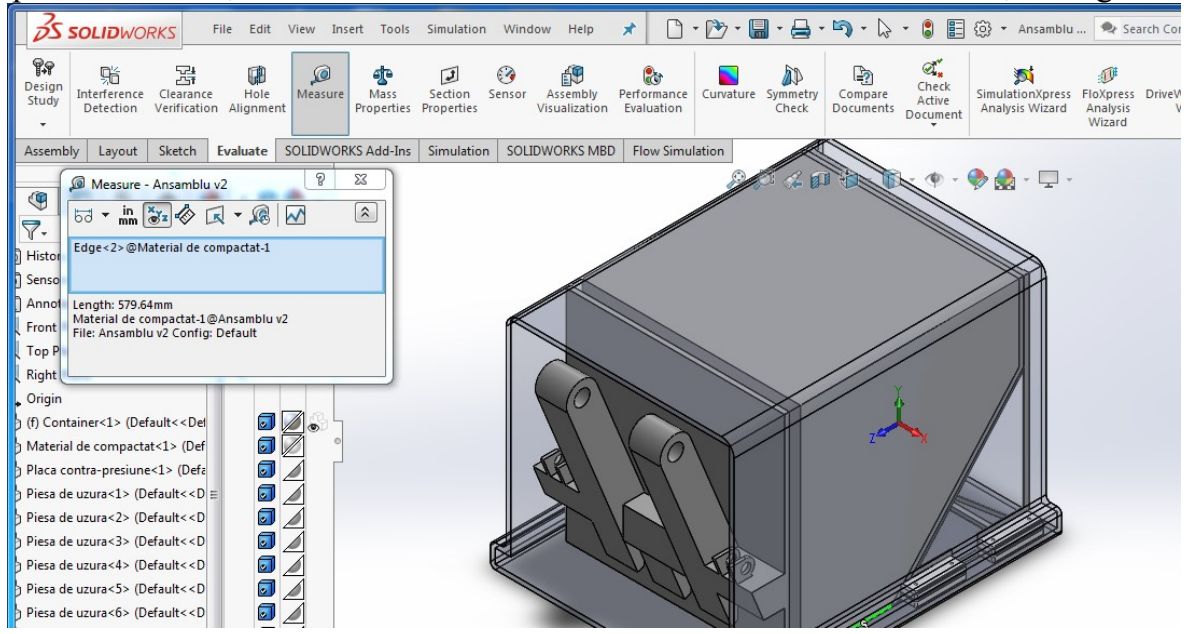

Fig. 3 The assembly introduced in the Motion Study module

The whole assembly of fig. 3 was introduced in the Motion Study module to perform the dynamic simulation of the compaction process of household waste. For this purpose it was considered that the back pressure plate is fixed, together with the compacted material, and the compactor plate moves. According to Manring N et al. [6], the speed of movement of the compaction plate without load is of maximum $150 \mathrm{~mm} / \mathrm{s}$, at the beginning of the compaction process the displacement speed is $75 \mathrm{~mm} / \mathrm{s}$ and reaches the end of the compaction at $20 \mathrm{~mm} / \mathrm{s}$. Thus, a variable speed linear motor was attached to the compaction plate (see fig. 4). It should also be mentioned that the calculation period (dynamic simulation) was $12 \mathrm{~s}$.

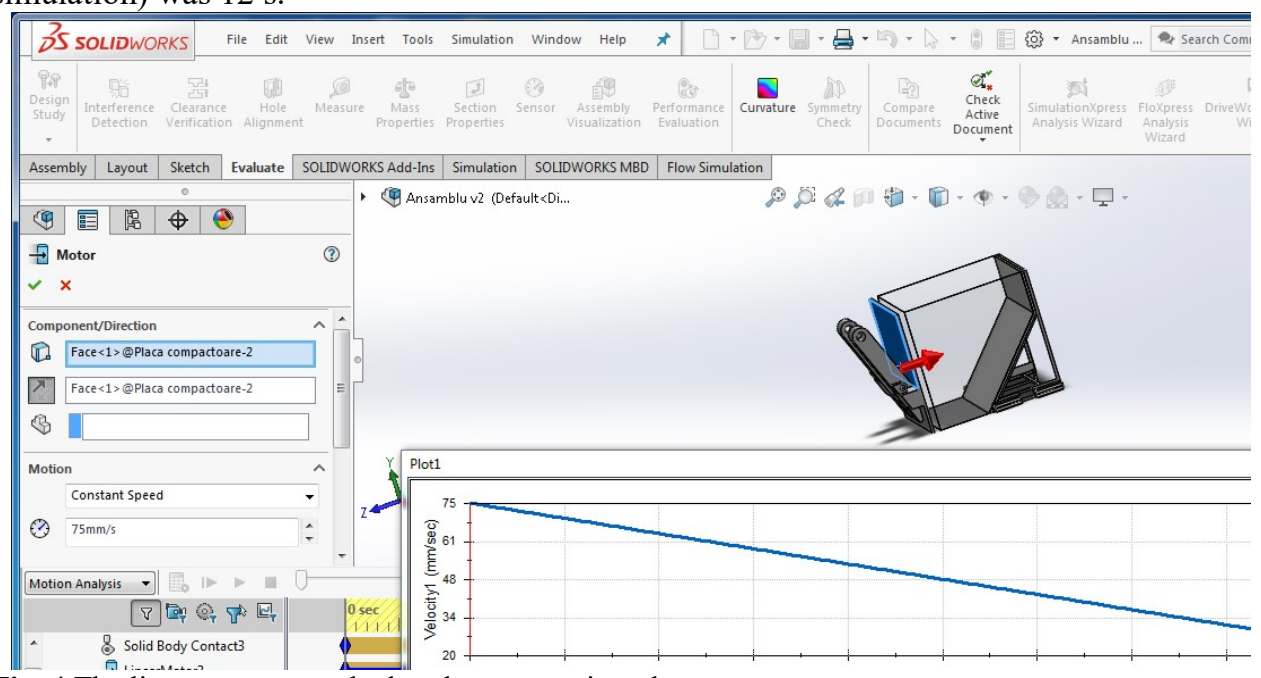

Fig. 4 The linear motor attached to the compaction plate

After completing this step, proceeded to the next step which was to import the stresses for the 3D geometric model of the compaction plate in the "Simulation" module of the Solid Works design program. 
According to the manufacturers specifications, the materials most often used in the manufacture of compression plates are Hardox 400, Hardox 450 and S355J2 steels. The characteristics of these three steels are presented in table 1, and in fig. 5 are shown the fatigue resistance curves of the three materials.

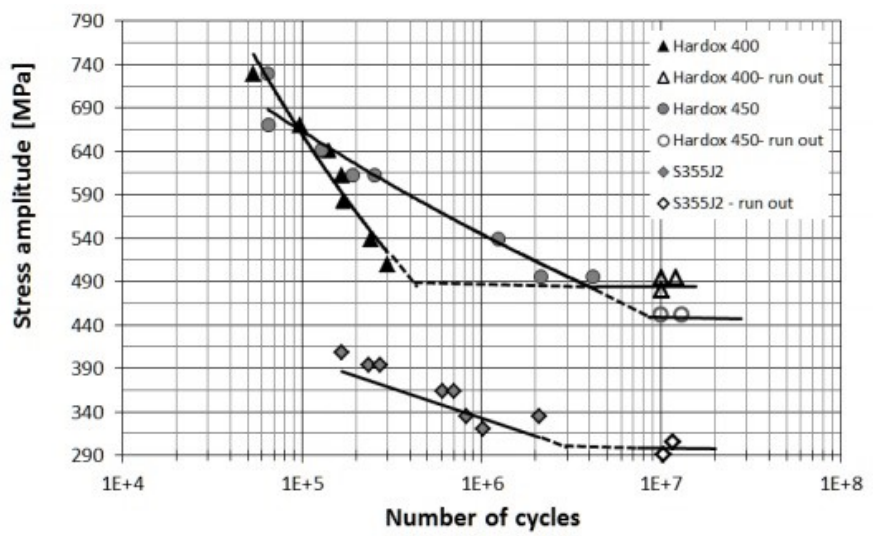

Fig. 5 Fatigue curves for Hardox 400, Hardox 450 and S355J2 steels [7-9]

Table 1. Mechanical properties of Hardox 400, Hardox 450 and S355J2 steels, [10-14]

\begin{tabular}{|c|c|c|c|}
\hline Mechanical property $\quad$ Material & Hardox 400 & Hardox 450 & S355J2 \\
\hline Elasticity modulus, $\mathrm{N} / \mathrm{mm}^{2}$ & 190000 & 200000 & 210000 \\
\hline Poisson's ratio, - & 0.29 & 0.3 & 0.3 \\
\hline Shear modulus, $\mathrm{N} / \mathrm{mm}^{2}$ & 75000 & 78000 & 80000 \\
\hline Density, $\mathrm{kg} / \mathrm{m}^{3}$ & 8000 & 8100 & 7800 \\
\hline Tensile strength, $\mathrm{N} / \mathrm{mm}^{2}$ & 1250 & 1663 & 630 \\
\hline Yield point, $\mathrm{N} / \mathrm{mm}^{2}$ & 1020 & 1350 & 665 \\
\hline Coefficient of thermal expansion, $1 / \mathrm{K}$ & $1.8 \mathrm{e}-005$ & $1.5 \mathrm{e}-005$ & $1.3 \mathrm{e}-005$ \\
\hline Thermal conductivity, $\mathrm{W} /(\mathrm{m} \cdot \mathrm{K})$ & 16 & 27 & 40 \\
\hline Specific heat, $\mathrm{J} /(\mathrm{kg} \cdot \mathrm{K})$ & 500 & 520 & 470 \\
\hline
\end{tabular}

\section{Results and discussions}

The finite element discretized model of the compression plate is presented in fig. 6 (there can be seen the characteristics of the mesh formed from 17904 nodes). After the discretization of the finite element network the simulation was run, its results being presented in the following. It should be noted that the simulation was performed with the "Large displacement" option selected.

Following the simulation, the design program provided the results obtained in graphical form; the geometric pattern is divided into areas of a certain colour, each area comprising the region of the geometric model in which the analysed size has the value specified in the chromatic legend on the right side of the screen. It should be noted that three simulations were run, one for each of the three chosen steels (Hardox 400, Hardox 450 and S355J2). 


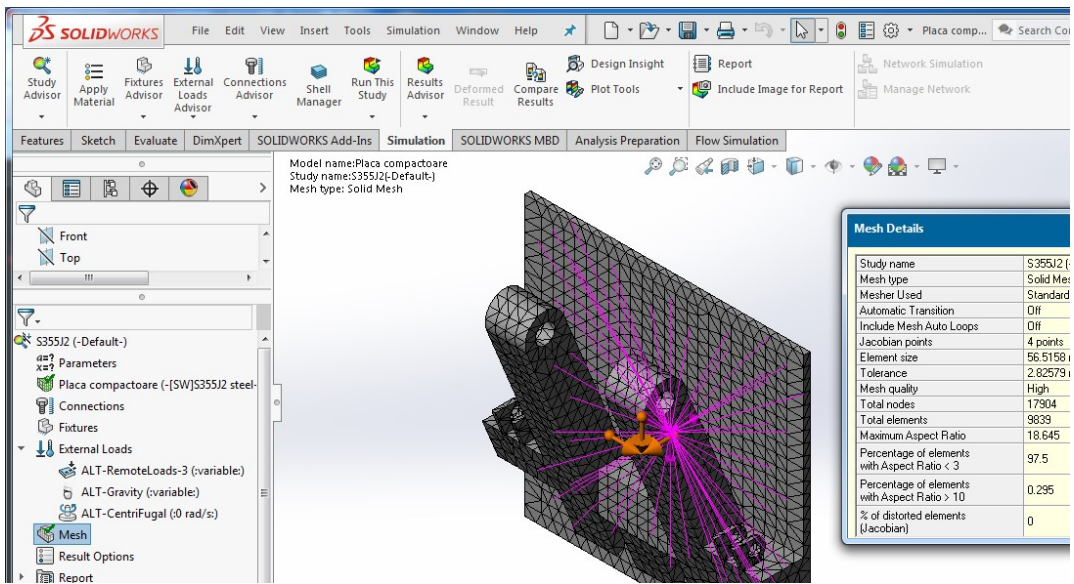

Fig.6. Finite element discretization of the geometric model

For the model of compression plate modelled and analysed, the results obtained from the simulation in Solid Works are presented below. Thus, in fig. 7 the values of the displacements that appear in the compression plate are presented during the stresses defined above.

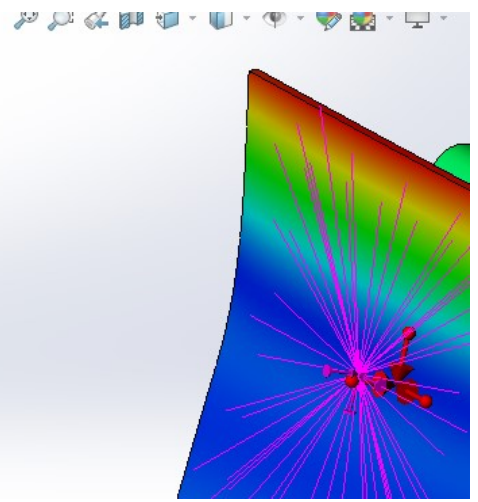

a. Hardox 400

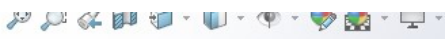

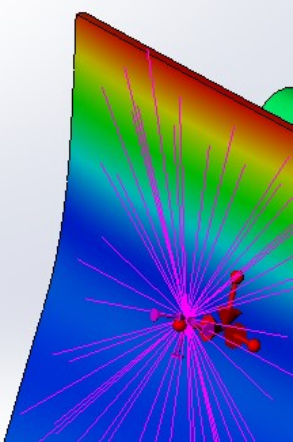

b. Hardox 450

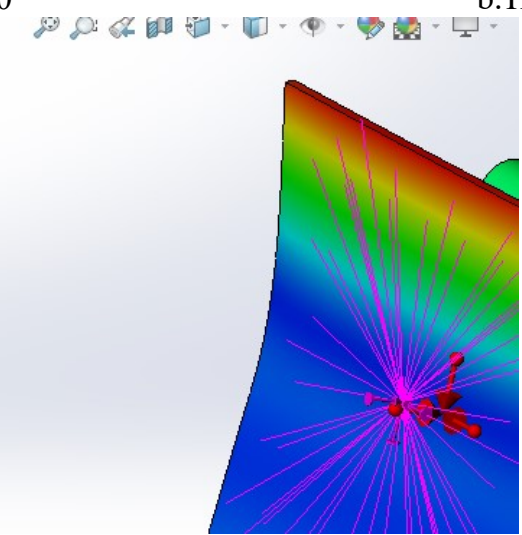

c. $\mathrm{S} 355 \mathrm{~J} 2$

Fig. 7. The values of displacements in the compression plate

Analysing this data, it can be seen that the values of the displacements are close (179 $\mu \mathrm{m}$ for Hardox 400, $170 \mu \mathrm{m}$ for Hardox 450 and $162 \mu \mathrm{m}$ for S355J2). Although S355J2 
steel is not necessarily a harder material than Hardox 450, it has the least displacement during the compaction process. For all three materials, the maximum displacement appears at the top of the compaction plate.

In fig. 8 the values of the equivalent stresses in the compaction plate are presented for the three analysed cases, stresses calculated according to von Mises criterion.

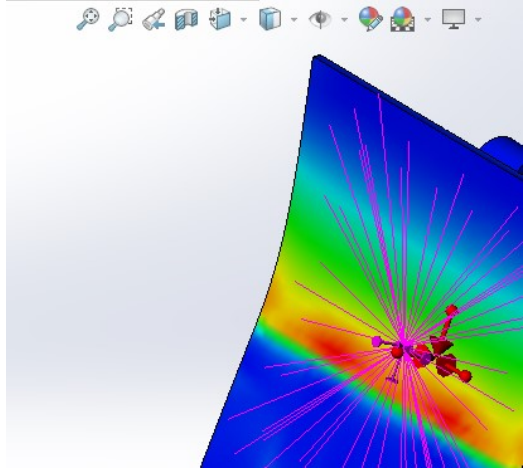

a. Hardox 400

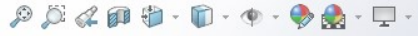

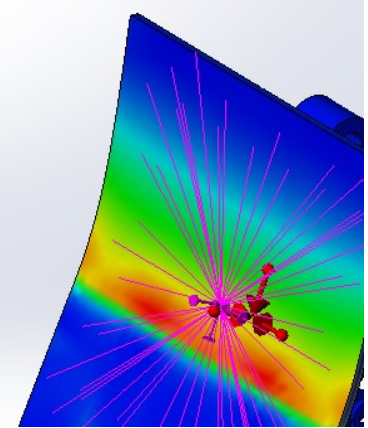

b. Hardox 450

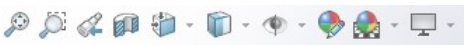

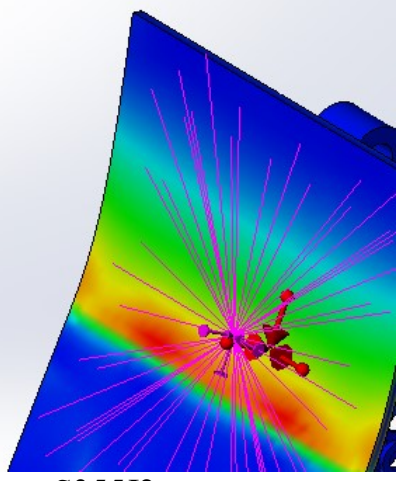

c.S355J2

Fig.8. Equivalent stress values according to von Mises criterion

Analysing the figure it can be observed that the highest equivalent stresses appear in the middle area of the compression plate structure, and their values are well below the breaking stresses of the three materials.

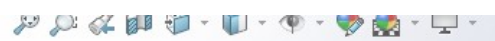

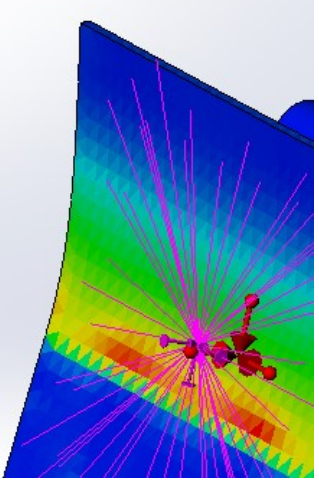

a. Hardox 400

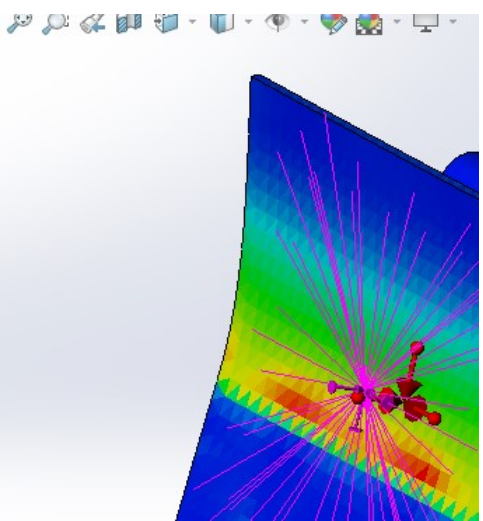

b. Hardox 450 


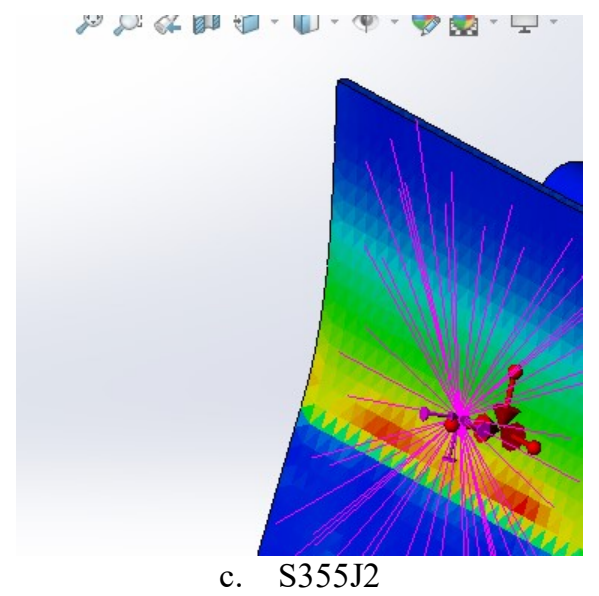

Fig. 9. The values of equivalent deformations occurring in the compression plate

Analysing fig. 9 we can observe the values of equivalent deformations that appear in the compression plate following the stresses to which it is subjected. So, the maximum equivalent deformation also emerges in the median area of the compression plate, the value of the deformations for the three materials considered being presented in the figure.

In fig. 10 the oscillation of the safety coefficient in the compression plate for the three materials considered is presented.

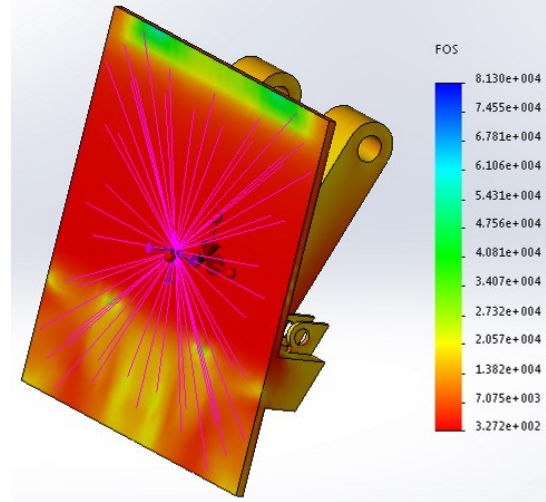

a. Hardox 400

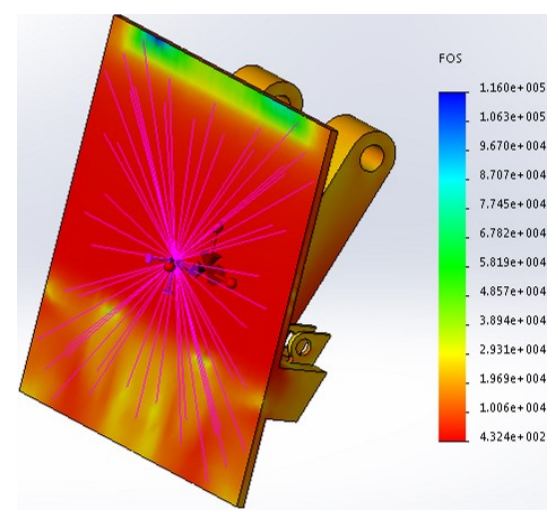

b. Hardox 450

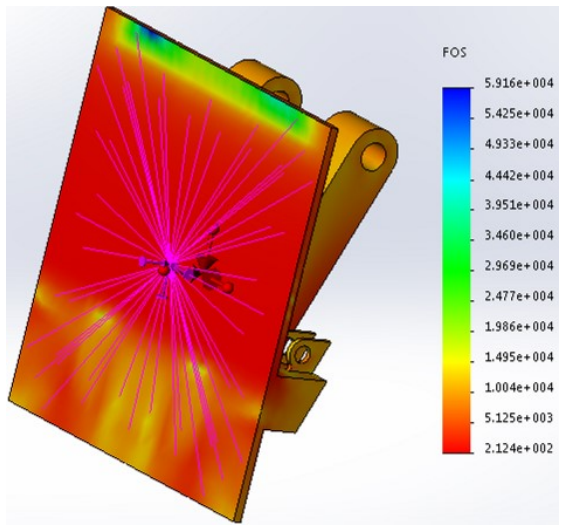

c. $\mathrm{S} 355 \mathrm{~J} 2$

Fig. 10. The variation of the safety coefficient for the three materials considered

The minimum value of the safety coefficient is reached for S355J2 steel, a steel with 
weaker mechanical properties compared to the other two and the maximum value is reached for Hardox 450, a steel with a rather high hardness. The minimum and maximum values are shown in the figure above. For comparison, for agricultural machines intended for ploughing, so machines that work in heavier conditions than the compression plate from the garbage truck, the coefficient of safety takes values between 1.8 and 2.2, [15].

\section{Conclusions}

The minimum values of the safety coefficient are 327 for Hardox 400, 432 for Hardox 450 and 212 for S355J2. It can be said that this compression plate is either oversized, either it is made to work in much heavier conditions than those provided by this study, or to withstand even overload (impact with hard to compact materials, excessive friction, etc.). The analysis also showed that in the compression plate structure appear stress concentration points, located in the areas where the plate is welded to the supports that connect to the drive yoke. The maximum values of the equivalent stresses calculated with the von Mises criterion are $3.118 \cdot 10^{6} \mathrm{MPa}$ for Hardox $400,3.122 \cdot 10^{6} \mathrm{MPa}$ for Hardox 450 and of $3.131 \cdot 10^{6} \mathrm{MPa}$ for S355J2, values somewhere in the middle of the yield point of these materials. Taking into account the above, the next step in completing the study would be a design analysis of the compaction plate. The results presented in this paper can be useful to designers and manufacturers of household compaction machines, but not only.

The paper was funded both from the project "Sustainable development of the base of agromechanical applications in gardens, solariums, vineyards and orchards (DEZDURPRA)", CNFIS-FDI-2020-0184, from the Ministry of Education and Research through the Executive Agency for Financing Higher Education, Research, Development and Innovation, as well as from the European Social Fund within the Sectoral Operational Program Human Capital 2014-2020, through the Financial Agreement of the project "Scholarships for entrepreneurial education between doctoral students and postdoctoral researchers (Be Entrepreneur!)", Contract no. 51680 / 09.07.2019 - SMIS Code: 124539.

\section{References}

1. P. Milosavljević, S. Jovanović, D. Jovanović, G. Radoičić, V. Blagojević, FACTA UNIVERSITATIS Series: Mechanical Engineering, 8, 1, (2010);

2. C. Sticlaru, A. Davidescu, Facta Universitatis, Mechanical Engineering, 2, 1, (2004);

3. M.T. Lates, Finite elements method, aplication (Metoda elementelor finite, aplicații), (Ed. Universității Transilvania, Brașov, 2008);

4. S. Guanglin; C. Shuxun; L. Guangmin, International Conference on Measuring Technology and Mechatronics Automation, (2009);

5. *** (2005), Value Pack, Service manual, Geesing Norba Group, Model year 2005

6. N. Manring, R. Fales, Hydraulic Control Systems, Second Edition, (Wiley, 2020);

7. R. Ulewicz, P. Szataniak, F. Novy, Conference proceeding METAL (2014);

8. N. Stranghöner, D. Jungbluth, , 6th Fatigue Design conference, (2015);

9. M. Mazur, R. Ulewicz, Applied Engineering Letters, 2, 1, (2017);

10. *** www.mtladv.com/wp-content/uploads/2016/01/151_HARDOX_400_UK.pdf

11. F. Sergejev and M. Petrov, Estonian Journal of Engineering, 18, 3, (2012);

12. R. Ulewicz, M. Mazur, O. Bokuvka, , Transportation Engineering 41, 2 (2013)

13. *** https://www.oblibene.com/userdata/shopimg/gamaocel/file/datasheet/hardox/ Data_sheet_2062uk_Hardox_450_Sheet_2016-03-02_85_371857150_en.pdf

14. $* * *-{ }^{\prime}$ http://www.joostdevree.nl/bouwkunde2/jpgs/staal_23_standaarden_s355_ european_standard_steel.pdf

15. G. Gheorghe, C. Persu, I. Gageanu, D. Cujbescu, 47th Int. Sym. “Actual Tasks on Agricultural Engineering”, (2019). 